\title{
Estudo sobre a aplicabilidade de adesivos biológicos à reinserção de músculo ocular externo em coelhos - I Experimento I - Medidas dos tempos dos procedimentos, das forças de adesão mioescleral e estudos clínico e histopatológico
}

\author{
A study of the applicability of biological adhesives to the reinsertion of an \\ external ocular muscle in rabbits - I \\ Experiment I-Measurements of duration of procedures, and clinical and \\ histopathologic studies
}

\author{
Beatriz Simões Corrêa ${ }^{1}$ \\ Harley Edison Amaral Bicas ${ }^{2}$
}

\begin{tabular}{|l|}
\hline RESUMO \\
\hline Objetivos: Medir o tempo da operação, as forças de adesão tecidual e fazer \\
estudo clínico e histopatológico de reinserções oculares de retos superio- \\
res de coelho com quatro diferentes adesivos teciduais, como alternativa \\
à utilização de sutura de poliglactina em operações de estrabismo. Méto- \\
dos: Cem coelhos da raça Nova Zelândia foram distribuídos em dois \\
experimentos, I-A e I-B, de cinqüenta coelhos cada, e estes em cinco \\
grupos de dez coelhos (vinte olhos), submetidos à operação de desinserção \\
do músculo reto superior de ambos os olhos, e reinserção com sutura \\
(controle) com poliglactina 910, 6-0 ou adesivos teciduais, de fibrina, \\
cianoacrilato, albumina-glutaraldeído e gelatina-resorcinol-formaldeído- \\
glutaraldeído. Os coelhos do experimento I-A foram submetidos à dinamo- \\
metria nos dez minutos após o reposicionamento muscular. Os coelhos do \\
experimento I-B foram submetidos à avaliação clínica e histopatológica. \\
Resultados: Verificou-se melhor desempenho dos adesivos teciduais no \\
tempo gasto para realizar a operação. Quanto à força de adesão, nenhum \\
dos adesivos apresentou 100\% de casos com resistência à tensão igual ou \\
maior que 100 gf. Com relação às avaliações clínica e histopatológica, \\
quanto à presença dos sinais inflamatórios e suas intensidades o adesivo \\
fibrínico utilizado neste trabalho apresentou melhor desempenho do que \\
a sutura de poliglactina 910, tendo os demais adesivos apresentado \\
resultados piores, quando comparados aos do grupo controle (sutura). \\
Conclusão: Os adesivos estudados mostraram-se inadequados para as \\
operações de estrabismo.
\end{tabular}

Descritores: Adesivos teciduais; Músculos oculomotores/cirurgia; Estrabismo/cirurgia; Adesivo tecidual de fibrina/uso terapêutico; Poliglactina 910; Suturas; Coelhos

\section{INTRODUÇÃO}

Adesivos biológicos são substâncias que, em contato com o organismo, polimerizam-se fixando os tecidos entre si.

Considerando, a contar de meados do século passado, o avanço tecno- 
lógico na produção e oferta de adesivos biológicos, de emprego cirúrgico generalizado, é razoável admitir que as objeções levantadas contra a aplicabilidade deles às operações de estrabismo possam tornar-se improcedentes. Supõe-se que alguns desses adesivos interfiram menos na estrutura muscular, ou causem menor reação inflamatória e cicatricial; se utilizados nas operações de estrabismo, como alternativa ao método da sutura, poderiam contribuir para minimizar a imprevisibilidade que tem caracterizado esse tipo de operação.

Disponíveis e amplamente utilizados em outras especialidades, existem vários adesivos biológicos; em desenvolvimento, existem outros tantos. Estão agrupados, segundo seu desempenho químico, como: 1) selantes de fibrina; 2) compostos de albumina; 3) compostos de gelatina-resorcinol-formaldeído-glutaraldeído; 4) cianoacrilatos; 5) hidrogéis e 6) compostos de colágeno ${ }^{(1)}$.

Os adesivos teciduais de cianoacrilato e os de fibrina, desenvolvidos entre 1950 e 1960, não apresentaram, na época, condições adequadas à aplicação em Medicina. Ultimamente, entretanto, novos derivados de cianoacrilato já não desenvolvem as intensas reações teciduais que o original desenvolvia. A evolução das técnicas laboratoriais permitiu melhores sínteses do adesivo fibrínico, bem como melhores técnicas de aplicação. Daí o fato de esses dois adesivos já estarem sendo amplamente utilizados em outras especialidades; não, porém, em operações de músculos oculares externos, acerca das quais poucas são as referências conhecidas.

1) Quanto aos cianoacrilatos, a força de adesão tecidual avaliada por Dunlap e colaboradores não apresentou resultados satisfatórios; quanto às avaliações histológicas reações teciduais mínimas a moderadas. Encontraram também fibras musculares que se regeneraram fora do local da reinserção ${ }^{(2)}$. Ricci e colaboradores encontraram forças de adesão satisfatórias avaliando um dia após a operação ${ }^{(3)}$. Villaseñor-Solares, Aguirre-Aquino citam bons resultados com o uso de cianoacrilato em operações de estrabismo(4).

2) Quanto aos adesivos fibrínicos, autores, relatam resultados histopatológicos satisfatórios. Com o sucesso de seus experimentos, passaram a usar em seres humanos, referindo cem pacientes operados ${ }^{(5-6)}$.

Outros autores, encontraram músculos mais deslizados nos pequenos recuos e menos nos grandes recuos ${ }^{(7)}$. Demonstraram ser possível ajustar o tempo de coagulação do adesivo controlando a concentração de trombina.

Outros pesquisadores, utilizando adesivo fibrínico desenvolvido na Universidade do Paraná concluíram que a força de adesão aumenta progressivamente com o tempo de pós-operatório, aproximando-se da produzida pela poliglactina-910, porém não obtiveram boa função muscular em todos os casos estudados ${ }^{(8-9)}$.

3) $\mathrm{Na}$ literatura especializada, não localizamos, com os adesivos de fibrina e cianoacrilato, estudos sobre forças de adesão após o término do efeito anestésico, em que forças inervacionais ativas podem modificar a posição onde foi reinserido o músculo.
4) Igualmente, não localizamos referências a respeito da extrusão total ou parcial dos cianoacrilatos, que são materiais não biodegradáveis e nem bioabsorvíveis.

5) Da mesma forma, não encontramos referências à utilização de adesivos de albumina-glutaraldeído e de gelatina-resorcinolglutaraldeído-formaldeído em músculos oculares externos.

\section{Adesivos}

\section{1) Adesivo de cianoacrilato}

Os adesivos do grupo cianoacrilato foram primeiro descritos em 1949. Esses adesivos polimerizam-se, numa reação exotérmica, quando em contato com fluidos ou substâncias básicas, formando uma aderência forte.

Os cianoacrilatos com cadeia alcoil curta, tal como o metilcianoacrilato, são extremamente flexíveis; a variante butil é menos flexível. Durante a polimerização, todos os cianoacrilatos liberam calor; a quantidade de calor liberada depende do tamanho da cadeia, sendo tanto maior quanto menor esta for. O comprimento da cadeia alcoil lateral é de decisiva importância para a velocidade da polimerização, para a ação adesiva e para a reação tecidual resultante da produção de calor.

Os efeitos tóxicos desses polímeros estão relacionados com sua degradação, quando há liberação de formaldeído e outros produtos. Os derivados metil degradam-se rapidamente, enquanto as cadeias maiores degradam-se muito devagar, sendo mais bem toleradas por tecidos vivos.

O poder adesivo é maior com o n-butil e o iso-butil-cianoacrilatos, decrescendo com as variantes de cadeia maior, na seguinte ordem: hexil, octil e decil-cianoacrilatos ${ }^{(10)}$.

Tais produtos, por não serem bioabsorvíveis, se não forem usados topicamente, podem induzir reação de corpo estranho, inflamação e necrose tecidual ${ }^{(1,5)}$.

\section{2) Adesivo de fibrina}

Os adesivos fibrínicos padronizados são obtidos pela mistura de dois componentes. O primeiro é o concentrado de fibrinogênio/fator VIII/fibronectina. O segundo, um concentrado de trombina obtido do plasma humano. Radosevich analisa a evolução do adesivo fibrínico desde 1940, e suas propriedades adesivas ótimas desenvolvidas com tecnologia de fracionamento para obter-se fibrinogênio concentrado. A trombina, uma protease coagulante do fibrinogênio, é essencial para regular a velocidade da polimerização do fibrinogênio em fibrina. Esses componentes, geralmente liofilizados, são solubilizados antes do uso com soluções de aprotinina (produto antifibrinolítico, cuja função é inibir ou tornar mais lenta a degradação do coágulo por uso de enzimas proteolíticas). A mistura dos dois componentes, na presença do cálcio ionizado, $\mathrm{CaCl}_{2}$, reproduz a última fase do complexo processo da coagulação e conduz à polimerização gradual do fibrinogênio, principal proteína estrutural do sangue que, com as plaquetas, forma os coágulos ${ }^{(11)}$. 


\section{3) Adesivo de gelatina-resorcinol-formaldeído-glutaraldeído}

É utilizado em cirurgia cardiovascular e cirurgia torácica, na correção do aneurisma dissecante de aorta e no bloqueio de fístulas brônquicas, em neurocirurgia, nas suturas de duramáter, na correção cirúrgica de fístulas liquóricas etc. e, em cirurgia geral, na hemostasia de órgãos parenquimatosos.

Foi pouco experimentado em operações oculares. Dos dois trabalhos encontrados, um ${ }^{(12)}$ analisa resultados macroscópicos e microscópicos das incisões corneanas coladas com o adesivo e conclui que o produto é de fácil utilização, de pequena toxicidade e teoricamente superior aos adesivos de cianoacrilato, pelas suas características de flexibilidade e biodegradabilidade. O outro é um estudo experimental na operação de conjuntiva de coelhos ${ }^{(13)}$. Os autores observam intensa reação inflamatória local e intra-ocular (irite, uveíte, coroidite, necrose com perfuração de tecidos) e concluem que o adesivo não se presta para operações conjuntivais.

\section{4) Adesivo de albumina-glutaraldeído}

Pertence ao grupo de albumina associada a compostos adesivos. Não apresenta em sua constituição o formaldeído, por suas características tóxicas teciduais. Seus efeitos inflamatórios e reações teciduais em longo prazo precisam ser mais bem conhecidos ${ }^{(1)}$.

Em estudo experimental em cirurgia torácica, esse adesivo foi utilizado para selar bronquiotomias em carneiros e anastomoses traqueais em ratos. Avaliações macroscópicas mostraram forte fechamento das anastomoses em todos os estágios pós-operatórios, inicialmente pela camada do adesivo, tardiamente pelo tecido cicatricial. Análises histológicas mostraram indução de proliferação de tecido fibroso envolvendo o adesivo e resposta tecidual de característica granulomatosa ${ }^{(14)}$.

\section{Objetivos}

Tivemos como objetivos neste trabalho:

a) Medir a força necessária para romper a junção mioescleral operada com a sutura convencional e com os adesivos teciduais.

b) Comparar os tempos de realização de operações realizadas com sutura e com os adesivos teciduais.

c) Observar os sinais clínicos: edema, hiperemia e secreção pós-operatórios.

d) Avaliar histopatologicamente a reação tecidual aos adesivos.

\section{MÉTODOS}

\section{Experimento I}

O estudo foi constituído por duzentos olhos (cem coelhos machos da raça Nova Zelândia, com peso entre 2 e 2,5 kg), divididos em dois experimentos, A e B, contendo, cada experimento, cem olhos (cinqüenta coelhos).
Em todos os casos, os animais foram submetidos à operação de desinserção do músculo reto superior bilateralmente, com reposicionamento por sutura (grupo controle), ou adesivo tecidual.

Os cem olhos (cinqüenta coelhos) de cada experimento (A e B) foram divididos em cinco grupos homogêneos (vinte olhos, dez coelhos), de acordo com o material usado para reposição escleral do músculo ocular:

1. Grupo SP: (controle): Sutura de poliglactina-910 (Vicryl ${ }^{\circledR}$ 6-0, Ethicon).

2. Grupo AC: Adesivo de cianoacrilato, n-butil-2 cianoacrilato (Histoacryl ${ }^{\circledR}$, B. Braun).

3. Grupo AF: Adesivo de fibrina (Beriplast- $\mathrm{P}^{\circledR}$, Centeon).

4. Grupo AA: Adesivo de albumina e glutaraldeído (Bioglue $^{\circledR}$, Cryolife).

5. Grupo AG: Adesivo de gelatina, resorcinol, formaldeído e glutaraldeído (Colagel $^{\circledR}$, Cirumédica).

Foram analisados os seguintes parâmetros: a) tempo de operação nos dois olhos, nos experimentos A e B; b) Medidas da força de ruptura da junção mioescleral, por dinamômetro mecânico, com precisão de um grama, dez minutos após o reposicionamento do reto superior previamente desinserido, no experimento A; c) sinais pós-operatórios de edema, hiperemia e secreção no experimento B; d) presença de alterações histológicas de inflamação, necrose, granuloma e fibrose, no experimento B.

Foram observados os critérios de cuidados com animais da Association for Research in Vision and Ophthalmology (ARVO) para a realização desse experimento.

\section{Técnica cirúrgica}

As anestesias utilizadas foram de dois tipos: a) geral, com Zoletil ${ }^{\circledR} 50$ (cloridrato de tilamina $125 \mathrm{mg}$ e cloridrato de zolazepan $125 \mathrm{mg}$ ), por meio de aplicação intramuscular na região glútea, nos volumes de 1 a $1,5 \mathrm{ml}$, com duração de trinta a quarenta minutos; b) local, com colírio anestésico de cloridrato de proparacaína a $0,5 \%$, instilado no fundo de saco conjuntival, antes e durante a operação. Complementada com injeção intramuscular de $0,1 \mathrm{ml}$ de atropina $1 \mathrm{mg}$.

Os procedimentos iniciaram-se com a anestesia do animal e assepsia dos pelos ao redor dos olhos com solução iodada. O coelho colocado na mesa cirúrgica, em decúbito lateral, sobre campo esterilizado e sob campo fenestrado, com exposição da região ocular, sendo operado o olho direito e, depois, o esquerdo, da seguinte maneira:

a. Abertura das pálpebras com blefarostato de Castroviejo.

b. Abertura da conjuntiva e cápsula de Tenon, com incisão de 2 a $3 \mathrm{~mm}$, paralela ao limbo, na região compreendida entre duas e dez horas e incisões radiais ao limbo realizadas nas posições de duas e dez horas.

c. Isolamento dos músculos: reto superior e oblíquo superior. Este, no coelho, prende-se à esclera junto à inserção do reto superior (Figura 1).

d. Preensão e miectomia do oblíquo superior, para sua retração na órbita, sem interferência nos resultados de procedimentos no reto superior. 


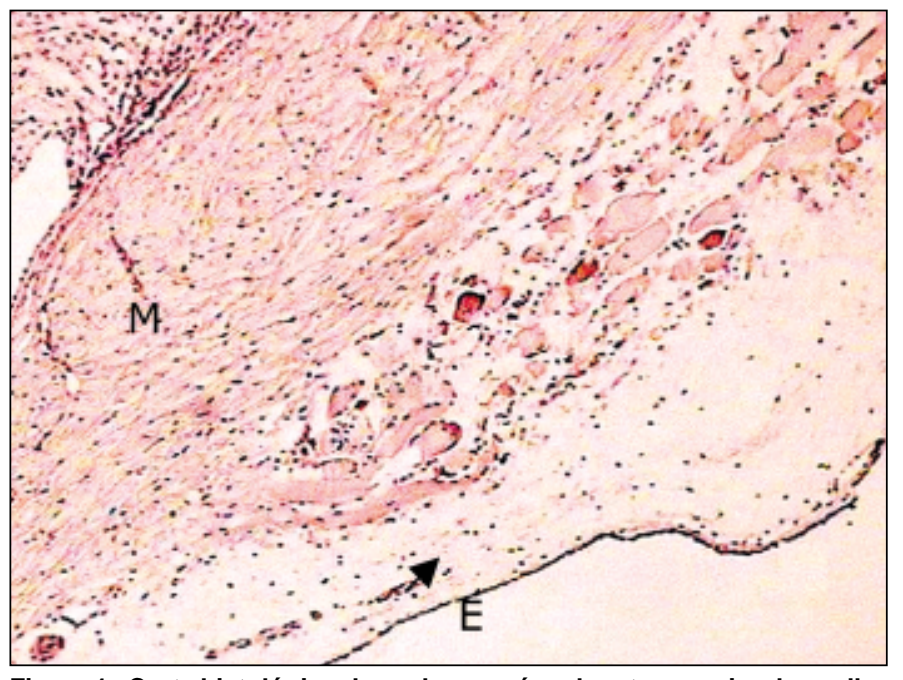

Figura 1 - Corte histológico de esclera e músculo reto superior de coelho (X10, HE) mostrando toda a extensão da inserção muscular, e a esclera adjacente (ausência de tendão). A letra $M$ refere-se ao tecido muscular, e a letra E, ao tecido escleral. A seta mostra a região da inserção muscular

e. Secção do reto superior, previamente, fixado por uma pinça (este músculo, no coelho, não tem tendão (Figura 1).

f. Utilização de um dos cinco materiais de união mioescleral. Os adesivos foram aplicados após cuidadosa secagem prévia da esclera e do coto muscular, este fixado em suas extremidades por duas pinças com dente, e aposto sobre a esclera, no local da inserção original com compressão do músculo com espátula de íris, durante o tempo adequado a cada adesivo aplicado.

g. Aposição da conjuntiva, sem sutura, sobre o local original. Grupo SP, sutura de poliglactina 910: O fio de sutura, partido em dois, foi passado a $1 \mathrm{~mm}$ dos limites laterais do músculo, que a seguir, foi reinserido no mesmo local com dois nós simples em cada extremidade.

Grupo AC, adesivo cianoacrilato, da seguinte maneira:

1. Retirada do adesivo do congelador uma hora antes da operação.

2. Abertura do cilindro, retirada a ampola de plástico estéril, cortada a ponta.

3. Aplicação do adesivo e compressão do músculo contra a esclera por cinco segundos.

Grupo AF, adesivo de fibrina: No produto comercial desse adesivo, as substâncias são apresentadas em embalagens separadas e hermeticamente fechadas: a de fibrinogênio e fator XIII (liofilizado) e a da aprotinina (solvente) ligadas por um tubo; da mesma forma, a de trombina (liofilizada) e de cloreto de cálcio (solvente). As substâncias são colocadas em contato no momento da aplicação, ao pressionar-se o tubo do solvente, permitindo sua transferência para o do liofilizado. $\mathrm{O}$ conteúdo de cada frasco, antes de ser usado, deve ser aspirado por duas seringas de insulina, a seguir são acopladas a um dispositivo que permite a saída independente de cada solução. Essas terão contato entre si no tecido a ser tratado. As agulhas que acompanham o "kit" foram substituídas por agulhas de calibre $13 / 3$, para redução da quantidade do adesivo a ser aplicado.

Aplicado o adesivo, compressão do músculo contra a esclera por um minuto.

A agulha foi trocada a cada nova utilização da cola (a agulha fica obstruída pelo coágulo que se forma em seu interior). Além disso, por variação do poder adesivo do produto (alguns "kits", experimentados várias vezes, não provocavam adesão tecidual) houve necessidade de utilização de vários "kits".

Grupo AA, adesivo de albumina e glutaraldeído: O produto é constituído de albumina bovina purificada (45\%) e glutaraldeído $(10 \%)$. Seus dois componentes, que vêm dentro de duas seringas acopladas, misturam-se no aplicador próprio, antes de sua aplicação na esclera. A aplicação desta cola foi feita na menor quantidade possível, uma vez que a viscosidade da mistura impede o uso de agulhas de calibre mais fino. Não houve dificuldade na utilização do produto. Após seu uso, irrigação exaustiva do olho com soro fisiológico.

Grupo AG, adesivo de gelatina, resorcinol, formaldeído, glutaraldeído. A preparação e a aplicação desse adesivo foram feitas da seguinte maneira: numa pequena cuba, colocados, aproximadamente, $1 \mathrm{~cm}^{3}$ da gelatina e uma gota da solução polimerizante, homogeneizados com uma espátula; a seguir colocação do adesivo sobre a esclera e, sobre esta, a imediata aposição da extremidade do músculo, aí fixado por dois minutos, com a espátula; imediatamente após, exaustiva irrigação do olho com soro fisiológico, para retirada de todos os resíduos. Observamos a formação de uma placa esbranquiçada sobre as inserções dos músculos aderidos à esclera por esse procedimento.

\section{Experimento I-A e I-B, tempo do procedimento}

\section{Medição do tempo do procedimento}

Foram feitas as medidas dos tempos dos procedimentos, de ambos os experimentos, A e B, com um cronômetro, iniciada sua marcação ao se colocar o blefarostato no primeiro olho a ser operado e finalizado o registro ao se retirar o blefarostato do segundo olho. Não foram considerados os tempos gastos no preparo dos adesivos.

\section{Experimento I-A, dinamometria}

\section{Técnica de medição da força de adesão tecidual}

Nos dez coelhos de cada um dos cinco grupos desse estudo (totalizando os cinquienta coelhos do experimento I-A), a força de adesão tecidual foi medida dez minutos após cada operação, com utilização de um dinamômetro mecânico Wagner, fabricado nos Estados Unidos, modelo FDK 025, com capacidade de até 100 gf, precisão de um gf. O procedimento foi o seguinte:

O gancho do dinamômetro era colocado sob o reto superior operado; a seguir, era tracionado o dispositivo marcador de força do aparelho até haver a ruptura da adesão mioescleral, ou chegar ao limite de 100 gf, da escala do dinamômetro. Não foram avaliadas forças maiores que $100 \mathrm{gf}$. 


\section{Experimento I-B, estudos clínico e histopatológico}

\section{Estudo clínico}

Os cinqüenta coelhos foram estudados no período préenucleação quanto ao edema, à hiperemia e à secreção ocular, cuja intensidade caracterizamos como ausente $(-)$, leve $(+)$, moderada (++), intensa (+++) e grave $(++++)$.

As enucleações de cada grupo estudado (com dez coelhos), obedeceram ao seguinte programa: no quarto dia, quatro olhos (dois coelhos), no sétimo dia, quatro olhos (dois coelhos,); no décimo-quarto dia, oito olhos (quatro coelhos); no quadragésimo dia, quatro olhos (dois coelhos). Desta forma, neste experimento I-B, tivemos até o quarto dia, dez coelhos em cada grupo; do quarto ao sétimo dia passamos a ter oito coelhos em cada grupo, do sétimo ao décimo quarto, seis coelhos, e do décimo quarto ao quadragésimo dia dois coelhos em cada grupo, com exceção do grupo AA, do qual os dois coelhos que seriam avaliados no quadragésimo dia foram sacrificados por terem apresentado intensas reações ao adesivo, e do grupo AG, em que um dos coelhos morreu antes do quadragésimo dia.

Colocação dos olhos enucleados em solução de formol a $10 \%$, (num volume oito vezes o volume do olho), os quais foram acondicionados, devidamente identificados nos coletores e encaminhados para o estudo histopatológico.

Sacrifício dos animais após o procedimento, com solução intracardíaca de cloreto de potássio $10 \%, 3 \mathrm{ml}$.

\section{Estudo histopatológico}

1. Fixação dos bulbos oculares em solução de formol a $10 \%$ por, pelo menos, vinte e quatro horas (máximo de setenta e duas horas);

2. Separação, por meio de lâmina de bisturi no 10 , de um retângulo de tecido do bulbo ocular, com esclera, limbo e inserção muscular, com sua maior medida paralela ao maior eixo do músculo;

3. Retirada de dois novos fragmentos do retângulo de tecido supracitado, incluídos em parafina, para tornar o fragmento resultante para a análise histopatológica uma representação da inserção muscular, em corte longitudinal das fibras musculares;

4. Processamento do fragmento do tecido em processador automático Leica Histology \& E.M. Products, TP 1020, segundo técnica padrão de processamento histológico;

5. Obtenção dos cortes histológicos de quatro micrômetros por micrótomo Leica Histology E.M. Products, RM 2145, com utilização de navalhas descartáveis Leica;

6. Coloração dos cortes histológicos com hematoxilinaeosina (HE) e van Gieson, para avaliação da deposição de colágeno no ponto de inserção muscular;

7. Avaliação histológica, realizada por um mesmo observador, sem conhecimento prévio da magnitude da resposta inflamatória observada clinicamente, utilizando um microscópio óptico Nikon, modelo eclipse E800;
8. Registro da intensidade ou magnitude da reação inflamatória foi avaliada como: leve, moderada ou intensa, levandose em conta o infiltrado inflamatório local; a presença ou ausência de necrose tecidual; a presença ou ausência de infiltrado crônico granulomatoso e a magnitude da deposição de colágeno (fibrose), quando presente. As imagens dos cortes histológicos foram obtidas com uma câmera digital Sony, modelo no SSC-DC 54 ${ }^{\mathrm{A}}$, acoplada ao microscópio, e um software, Microsoft ${ }^{\circledR}$ VidCap, Windows 98. Cortes histológicos com fragmentação excessiva, ou eventuais artefatos de processamento foram desprezados.

\section{Métodos estatísticos}

Os dados obtidos foram analisados utilizando-se:

1. Distribuição de freqüências e porcentuais.

2. Descrição estatística através das médias aritméticas, medianas, desvios padrões e variâncias.

3. Análise da variância para comparação da duração da operação entre as técnicas de adesão empregadas.

4. Teste de Tuckey para verificar quais as diferenças entre as médias que foram significativas.

5. Teste exato de Fisher para comparar as vantagens ou desvantagens de adesivos analisados em relação aos sinais pós-operatórios: clínicos (edema, hiperemia, secreção) e histopatológicos (inflamação, necrose, granuloma, fibrose).

6. O nível de significância adotado foi o de $5 \%$ (o valor de $\mathrm{p}<0,05)$.

\section{RESULTADOS}

Os resultados estão apresentados nas tabelas que se seguem, e descritas as observações macroscópicas no momento da enucleação.

Tabela 1: experimento I-A e I-B. Tempo da operação em cada coelho

Tabela 2: Experimento I-A. Resistência da junção mioescleral à tração

Tabela 3: Experimento I-B. Observações clinicas de edema, hiperemia e secreção ocular

Tabela 4: Observações histopatológicas de inflamação, necrose, granuloma e fibrose

\section{Análise dos resultados}

\section{Tempo de operação}

Com relação ao tempo da operação (Tabela 1), foram observadas diferenças significativas entre o emprego da sutura convencional e o dos adesivos teciduais. A duração da operação com a poliglactina 910 é significativamente maior do que a duração necessária para o emprego dos adesivos teciduais.

Aplicado o teste de Tuckey foram observadas diferenças significativas entre as médias aritméticas do grupo controle e as médias aritméticas dos demais grupos, com p-valor <0,01. 
Nas comparações entre si das médias aritméticas dos grupos dos adesivos, as diferenças foram consideradas não significativas, e o p-valor $>0,05$.

\section{Resistência do adesivo}

Sobre as medidas de resistência de adesão mioescleral (Tabela 2), tolerando-se como satisfatória a resistência a, no mínimo, 80 gf de tração, teríamos 20/20 (100\%) de casos de sucessos da sutura, $16 / 20(80 \%)$ do cianoacrilatoe $17 / 20(85 \%)$ do adesivo de fibrina. Aplicado o teste do Qui-quadrado para amostras independentes, com o p-valor $>0,05$, não houve diferença entre os resultados obtidos com a utilização desses três materiais. Os adesivos de albumina-glutaraldeído e gelatinaresorcinol-formaldeído-glutaraldeído, com 14/20 (70\%) e 8/20 (40\%) de sucessos, comparados com a sutura de poliglactina 910 , apresentaram valor de $\mathrm{p}<0,05 \mathrm{e}<0,01$, respectivamente, mostrando haver diferença na adesão tecidual entre os grupos dos adesivos mencionados e o controle, ou seja, o comportamento dos adesivos albumina-glutaraldeído e gelatina-resorcinol-formaldeído-glutaraldeído não foram considerados satisfatórios quanto à resistência de adesão mioescleral, mesmo com a tolerância assumida.

Se tomarmos como satisfatórias resistências de $100 \mathrm{gf}$ ou maiores, teremos: 20/20 (100\%) de sucesso do controle, 13/20 (65\%) do cianoacrilato, $16 / 20$ (80\%) do adesivo de fibrina, $12 / 20$ $(60 \%)$ do adesivo de albumina-glutaraldeído e 7/20 (35\%) do adesivo de gelatina-resorcinol-formaldeído-glutaraldeído.

\section{Observações clínicas de edema, hiperemia e secreção ocular}

Os resultados estão apresentados na tabela 3.

Aplicado o teste exato de Fisher, comparando o controle e o adesivo de fibrina no segundo dia, concluiu-se que os coelhos com a inserção muscular aderida pelo adesivo de fibrina tiveram menos edema, hiperemia e secreção que aqueles com inserção pela sutura ou com o cianoacrilato.

No $4^{0}$ dia, o adesivo de fibrina ainda apresentou melhores resultados que os da sutura e cianoacrilato, quanto à hiperemia e à secreção. No que tange ao edema, os resultados com a sutura foram também bons.

A partir do $14^{\circ}$ dia, não houve diferença significativa entre o controle e os adesivos de fibrina e cianoacrilato com relação ao edema, à hiperemia e à secreção. $\mathrm{O}$ adesivo de albuminaglutaraldeído (AA) e o de gelatina-resorcinol-formaldeídoglutaraldeído (AG) mostraram, sempre, piores resultados no $2^{\circ} \underline{0}, 7^{0}$ e $14^{\circ}$ dias quanto a edema, hiperemia e secreção.

\section{Observações macroscópicas dos olhos no momento da enucleação}

Nos quarto, sétimo e décimo-quarto dia encontramos quanto aos olhos operados com a sutura, os adesivos de fibrina e o cianoacrilato, pouca ou nenhuma secreção, e estruturas anatômicas preservadas. Quanto ao adesivo de albumina-glutaraldeído, encontramos edema, hiperemia e secreção com intensidades graves em todos os olhos enucleados, bem como estruturas anatômicas bastante comprometidas com presença de

\begin{tabular}{|c|c|c|c|c|c|c|}
\hline \multirow[b]{2}{*}{ Grupo } & \multirow[b]{2}{*}{ Coelho } & \multicolumn{5}{|c|}{ Tempo do procedimento (minutos) } \\
\hline & & SP & AC & AF & AA & AG \\
\hline \multirow[t]{10}{*}{ A } & 1 & 30 & 11 & 11 & 12 & 10 \\
\hline & 2 & 20 & 18 & 10 & 23 & 15 \\
\hline & 3 & 23 & 15 & 13 & 19 & 20 \\
\hline & 4 & 17 & 10 & 11 & 25 & 25 \\
\hline & 5 & 25 & 20 & 20 & 14 & 15 \\
\hline & 6 & 20 & 13 & 10 & 17 & 15 \\
\hline & 7 & 25 & 10 & 10 & 16 & 15 \\
\hline & 8 & 30 & 20 & 15 & 11 & 20 \\
\hline & 9 & 20 & 15 & 15 & 10 & 17 \\
\hline & 10 & 35 & 7 & 22 & 10 & 13 \\
\hline \multirow[t]{13}{*}{ B } & 1 & 19 & 13 & 15 & 12 & 13 \\
\hline & 2 & 30 & 7 & 12 & 15 & 23 \\
\hline & 3 & 33 & 12 & 7 & 7 & 11 \\
\hline & 4 & 30 & 12 & 8 & 8 & 7 \\
\hline & 5 & 22 & 10 & 22 & 22 & 15 \\
\hline & 6 & 20 & 23 & 11 & 11 & 25 \\
\hline & 7 & 22 & 7 & 10 & 10 & 21 \\
\hline & 8 & 20 & 5 & 20 & 20 & 18 \\
\hline & 9 & 30 & 5 & 11 & 11 & 15 \\
\hline & 10 & 35 & 8 & 10 & 10 & 17 \\
\hline & $\mathrm{m}$ & 25,1 & 12,1 & 13,3 & 14,3 & 16,8 \\
\hline & $\mathrm{s}$ & 5,8 & 5,3 & 4,6 & 5,4 & 4,7 \\
\hline & Mediana & 24 & 12 & 11 & 12 & 15 \\
\hline \multicolumn{7}{|c|}{$\begin{array}{l}\mathrm{SP}=\text { sutura de poliglactina } 910 ; \mathrm{AC}=\text { adesivo de cianoacrilato; } \mathrm{AF}=\text { adesivo } \\
\text { de fibrina; } \mathrm{AA}=\text { adesivo de albumina-glutaraldeído; } \mathrm{AG}=\text { adesivo de gelatina- } \\
\text { resorcinol-formaldeído-glutaraldeído }\end{array}$} \\
\hline
\end{tabular}

\begin{tabular}{|c|c|c|c|c|c|}
\hline \multirow[b]{2}{*}{ Olho } & \multicolumn{5}{|c|}{ Resistência do adesivo (gf) } \\
\hline & SP & AC & AF & AA & $\mathbf{A G}$ \\
\hline $\mathrm{D}$ & $100+$ & $100+$ & $100+$ & * & $100+$ \\
\hline$E$ & $100+$ & 50 & $100+$ & * & * \\
\hline D & $100+$ & $100+$ & $100+$ & $100+$ & 45 \\
\hline$E$ & $100+$ & 50 & $100+$ & * & 40 \\
\hline D & $100+$ & 60 & * & * & $100+$ \\
\hline$E$ & $100+$ & * & $100+$ & $100+$ & 75 \\
\hline D & $100+$ & $100+$ & * & $100+$ & 40 \\
\hline$E$ & $100+$ & $100+$ & * & $100+$ & 75 \\
\hline D & $100+$ & $100+$ & $100+$ & $100+$ & $100+$ \\
\hline$E$ & $100+$ & $100+$ & $100+$ & 80 & 32 \\
\hline D & $100+$ & 95 & $100+$ & $100+$ & 35 \\
\hline$E$ & $100+$ & $100+$ & $100+$ & $100+$ & 72 \\
\hline D & $100+$ & $100+$ & 90 & $100+$ & 75 \\
\hline$E$ & $100+$ & $100+$ & $100+$ & 70 & 71 \\
\hline D & $100+$ & 90 & $100+$ & $100+$ & $100+$ \\
\hline$E$ & $100+$ & $100+$ & $100+$ & 94 & $100+$ \\
\hline D & $100+$ & $100+$ & $100+$ & $100+$ & 35 \\
\hline$E$ & $100+$ & $100+$ & $100+$ & 41 & 80 \\
\hline D & $100+$ & 90 & $100+$ & $100+$ & $100+$ \\
\hline$E$ & $100+$ & $100+$ & $100+$ & $100+$ & $100+$ \\
\hline \multicolumn{6}{|c|}{$\begin{array}{l}\mathrm{SP}=\text { sutura de poliglactina } 910 ; A C=\text { adesivo de cianoacrilato; } \mathrm{AF}=\text { adesivo } \\
\text { de fibrina; } \mathrm{AA}=\text { adesivo de albumina-glutaraldeído; } \mathrm{AG}=\text { adesivo de gelatina- } \\
\text { resorcinol-formaldeído-glutaraldeído } \\
100+=\text { maior do que } 100 \mathrm{gf} \\
\text { * não fixação do músculo à esclera por descolamento, deslizamento imediato } \\
\text { após a aplicação, ou outra intercorrência }\end{array}$} \\
\hline
\end{tabular}


simbléfaro, neovascularização e leucomas na córnea. Bulbos oculares duros à depressão. Grande dificuldade para separar as estruturas, antes das enucleações. Quanto ao adesivo de gelatina-resorcinol-formaldeído-glutaraldeído observamos moderada intensidade da secreção em alguns olhos, em outros nenhuma reação tecidual aparente. Em um olho, o reto superior não foi encontrado; em outro, foi encontrado a $6 \mathrm{~mm}$ do limbo.

No quadragésimo dia encontramos estruturas anatômicas preservadas, sem edema, secreção ou hiperemia nos olhos enucleados de poliglactina 910, gelatina-resorcinol-formaldeído-glutaraldeído, fibrina e cianoacrilato.
Como decorrência da intensa reação pós-operatória ocorrida em todos os olhos operados com o adesivo de albuminaglutaraldeído, foi feita a colheita da secreção conjuntival de dois olhos e esfregaço a fresco, no décimo-quarto dia, tendo sido encontrados poucos cocos gram-negativos.

\section{Observações histopatológicas de inflamação, necrose, granuloma e fibrose (Tabela 4)}

Aplicado o teste não paramétrico exato de Fisher, comparando cada duas técnicas de fixação mioescleral entre si, obti-

\begin{tabular}{|c|c|c|c|c|c|c|c|c|c|c|c|c|c|c|c|c|}
\hline \multirow[b]{3}{*}{ Dia } & \multirow[b]{3}{*}{ Intensidade } & \multicolumn{15}{|c|}{ Sinal } \\
\hline & & \multicolumn{5}{|c|}{ Edema } & \multicolumn{5}{|c|}{ Hiperemia } & \multicolumn{5}{|c|}{ Secreção } \\
\hline & & SP & AC & AF & AA & $\mathbf{A G}$ & SP & AC & AF & AA & AG & SP & AC & $\mathbf{A F}$ & AA & AG \\
\hline \multirow[t]{3}{*}{$2^{\circ}$} & Satisfatório & 12 & 10 & 20 & 0 & 0 & 12 & 5 & 20 & 0 & 0 & 12 & 5 & 20 & 0 & 0 \\
\hline & Insatisfatório & 8 & 10 & 0 & 20 & 20 & 8 & 15 & 0 & 20 & 20 & 8 & 15 & 0 & 20 & 20 \\
\hline & Total & 20 & 20 & 20 & 20 & 20 & 20 & 20 & 20 & 20 & 20 & 20 & 20 & 20 & 20 & 20 \\
\hline \multirow[t]{3}{*}{$4^{\circ}$} & Satisfatório & 20 & 10 & 20 & 0 & 0 & 16 & 10 & 20 & 0 & 0 & 16 & 10 & 20 & 0 & 0 \\
\hline & Insatisfatório & 0 & 10 & 0 & 20 & 20 & 4 & 10 & 0 & 20 & 20 & 4 & 10 & 0 & 20 & 20 \\
\hline & Total & 20 & 20 & 20 & 20 & 20 & 20 & 20 & 20 & 20 & 20 & 20 & 20 & 20 & 20 & 20 \\
\hline \multirow[t]{3}{*}{$7^{0}$} & Satisfatório & 16 & 16 & 16 & 0 & 0 & 0 & 6 & 16 & 0 & 0 & 10 & 6 & 16 & 0 & 0 \\
\hline & Insatisfatório & 0 & 0 & 0 & 16 & 16 & 16 & 10 & 0 & 16 & 16 & 6 & 10 & 0 & 16 & 16 \\
\hline & Total & 16 & 16 & 16 & 16 & 16 & 16 & 16 & 16 & 16 & 16 & 16 & 16 & 16 & 16 & 16 \\
\hline \multirow[t]{3}{*}{$14^{\circ}$} & Satisfatório & 12 & 12 & 12 & 0 & 0 & 12 & 12 & 12 & 0 & 0 & 12 & 12 & 12 & 0 & 0 \\
\hline & Insatisfatório & 0 & 0 & 0 & 12 & 12 & 0 & 0 & 0 & 12 & 12 & 0 & 0 & 0 & 12 & 12 \\
\hline & Total & 12 & 12 & 12 & 12 & 12 & 12 & 12 & 12 & 12 & 12 & 12 & 12 & 12 & 12 & 12 \\
\hline \multirow[t]{3}{*}{$40^{\circ}$} & Satisfatório & 4 & 4 & 4 & * & 2 & 4 & 4 & 4 & * & 2 & 4 & 4 & 4 & * & 2 \\
\hline & Insatisfatório & 0 & 0 & 0 & * & 0 & 0 & 0 & 0 & * & * & 0 & 0 & 0 & * & * \\
\hline & Total & 4 & 4 & 4 & 0 & 2 & 4 & 4 & 4 & 0 & 2 & 4 & 4 & 4 & 0 & 2 \\
\hline \multicolumn{17}{|c|}{$\begin{array}{l}\mathrm{SP}=\text { sutura de poliglactina } 910 ; \mathrm{AC}=\text { adesivo de cianoacrilato; } \mathrm{AF}=\text { adesivo de fibrina; } \mathrm{AA}=\text { adesivo de albumina-glutaraldeído; } \mathrm{AG}=\text { adesivo de gelatina-resorcinol- } \\
\text { formaldeído-glutaraldeído } \\
\text { Nota: Os números em negrito representam valores menores do que o esperado do total da amostra, por perda do animal. * Sem amostras } \\
\quad \text { Satisfatório: - (ausente); + (leve) e Insatisfatório: ++ (moderada); +++ (intensa); ++++ (grave) }\end{array}$} \\
\hline
\end{tabular}

\begin{tabular}{|c|c|c|c|c|c|c|c|c|c|c|c|c|c|c|c|c|c|c|c|c|c|}
\hline \multirow[b]{3}{*}{ Dia } & \multirow[b]{3}{*}{ Intensidade } & \multicolumn{20}{|c|}{ Sinal } \\
\hline & & \multicolumn{5}{|c|}{ Inflamação } & \multicolumn{5}{|c|}{ Necrose } & \multicolumn{5}{|c|}{ Granuloma } & \multicolumn{5}{|c|}{ Fibrose } \\
\hline & & SP & AC & AF & AA & $\mathbf{A G}$ & SP & $A C$ & AF & AA & $\mathbf{A G}$ & SP & AC & AF & AA & $\mathbf{A G}$ & SP & AC & AF & AA & $\mathbf{A G}$ \\
\hline \multirow{2}{*}{$4^{0}$} & Insatisfatório & 0 & 2 & 0 & 4 & 1 & 0 & 0 & 0 & 3 & 0 & 0 & 3 & 0 & 0 & 0 & 0 & 0 & 0 & 0 & 0 \\
\hline & Total & 4 & 4 & 4 & 4 & 4 & 4 & 4 & 4 & $3^{*}$ & 4 & 4 & 4 & 4 & $3^{*}$ & 4 & 4 & 4 & 4 & $3^{*}$ & 4 \\
\hline \multirow[t]{2}{*}{$7^{\circ}$} & Satisfatório & 2 & 2 & 1 & 0 & 3 & 0 & 3 & 4 & 2 & 4 & 0 & 2 & 3 & 2 & 0 & 4 & 0 & 0 & 0 & 4 \\
\hline & Total & 4 & $3^{*}$ & 4 & 4 & 4 & 4 & $3^{*}$ & 4 & 4 & 4 & 4 & 4 & 4 & 4 & 4 & 4 & 4 & 4 & 4 & 4 \\
\hline \multirow[t]{3}{*}{$14^{\circ}$} & Satisfatório & 7 & 0 & 8 & 0 & 6 & 0 & 8 & 8 & 3 & 6 & 5 & 0 & 8 & 3 & 5 & 6 & 6 & 7 & 3 & 5 \\
\hline & Insatisfatório & 1 & 8 & 0 & 7 & 2 & 8 & 0 & 0 & 4 & 2 & 3 & 8 & 0 & 4 & 3 & 2 & 2 & 1 & 4 & 3 \\
\hline & Total & 8 & 8 & 8 & $7^{\star}$ & 8 & 8 & 8 & 8 & $7^{*}$ & 8 & 8 & 8 & 8 & $7^{*}$ & 8 & 8 & 8 & 8 & $7^{*}$ & 8 \\
\hline \multirow[t]{2}{*}{$40^{\circ}$} & Satisfatório & 1 & 2 & 0 & 0 & 0 & 4 & 4 & 4 & 0 & 2 & 4 & 3 & 4 & 0 & 0 & 4 & 2 & 4 & 0 & 2 \\
\hline & Insatisfatório & 2 & 1 & 4 & 0 & 0 & 0 & 0 & 0 & 0 & 0 & 0 & 0 & 0 & 0 & 2 & 0 & 1 & 0 & 0 & 0 \\
\hline
\end{tabular}


vemos nos períodos de avaliação, como mais significativos os seguintes resultados:

a) Para inflamação: entre a sutura de poliglactina 910 e o cianoacrilato no décimo-quarto dia, mostrou que o processo inflamatório dependeu do material, pior para o cianoacrilato e entre a sutura e o adesivo de albumina-glutaraldeído, pior para o adesivo de albumina-glutaraldeído.

b) Para necrose: no décimo-quarto dia, entre a sutura de poliglactina 910 e o cianoacrilato e a sutura de poliglactina 910 e o adesivo de fibrina, mostrou que o controle apresentou maior intensidade de necrose do que os outros materiais. As diferenças não foram significativas nos outros períodos.

c) Para granuloma: entre o adesivo de fibrina e o de cianoacrilato, mostrou diferença significativa na formação de granuloma pelo de cianoacrilato, comparado com o de fibrina.

d) Para fibrose: não houve diferença significativa entre os grupos.

\section{DISCUSSÃO}

Os achados sugerem que três dos quatro adesivos testados apresentaram desempenho melhor do que o controle, com relação ao tempo de operação: de fibrina, de cianoacrilato e de albumina-glutaraldeído. O desempenho do adesivo de gelatina-resorcinol-glutaraldeído-formaldeído foi semelhante ao do controle.

A força de adesão músculoescleral no grupo controle foi, em todos os casos, maior que $100 \mathrm{gf}$.

Com o adesivo de fibrina apesar de ter mostrado 16/20 medidas acima de 100 gf, apresentou uma com 90 gf e três amostras não aproveitadas, pois um músculo deslizou, outro não colou, e, no terceiro, a junção mioescleral foi rompida ao se passar o gancho para a dinamometria.

A resistência à tensão com os demais adesivos apresentou em mais de um caso, medidas inferiores a $100 \mathrm{gf}$.

Como nos movimentos oculares de perseguição, gradativamente, os retos agonistas desse movimento chegam a exercer $40 \mathrm{gf}$, quando estão a aproximadamente quarenta e cinco graus de rotação a partir da posição primária, e para um movimento sacádico, as unidades fibrilares rápidas solicitadas, dificilmente exercem forças superiores a $100 \mathrm{gf}^{(15-16)}$, consideramos os materiais cujas forças de resistência à tração tenham se apresentado, mesmo que em um caso, menores que $100 \mathrm{gf}$, inadequados para estas operações.

Quanto ao grupo controle, poliglactina 910, não houve nenhum caso com força de ruptura muscular inferior a $100 \mathrm{gf}, \mathrm{o}$ que torna esta técnica mais segura do que as outras.

Quanto às observações clínicas, tivemos melhor desempenho com o adesivo de fibrina do que com os outros materiais. Os adesivos de albumina-glutaraldeído e gelatina-resorcinol-formaldeído-glutaraldeído, apresentaram intensas reações teciduais.

À histopatologia, no grupo controle houve reação tecidual pequena, no quarto dia, aumentando discretamente no sétimo, no décimo-quarto e no quadragésimo dia. Estes resultados foram próximos aos de autores que, estudando respostas teciduais deste material implantado em músculos oculares de coelhos, encontraram reações pequenas até o vigésimo-primeiro dia, aumentando discretamente durante a absorção da sutura ${ }^{(17)}$.

$\mathrm{O}$ adesivo de cianoacrilato, apresentou reações teciduais moderadas no quarto e sétimo dia, mais intensas no décimoquarto dia, com maior reação granulomatosa e reações teciduais leves no quadragésimo dia. Outros pesquisadores, estudando as reações histológicas provocadas por este adesivo em músculos oculares externos de coelhos, verificaram em alguns cortes que a união entre músculo e esclera ocorreu por regeneração muscular à frente e talvez ao redor do material. Não observaram extrusão deste, a não ser em um espécime, em que foi encontrado adesivo livre na conjuntiva ${ }^{(2)}$. Os achados clínicos e o aspecto macroscópico da junção mioescleral, neste trabalho, assemelham-se aos de Dunlap. Diferem quanto aos achados histológicos, em que encontramos reação granulomatosa importante, como já descrito, e, quanto à extrusão do material, este foi encontrado livre em diversos olhos, sobre a conjuntiva ou aposto sobre junção músculoescleral.

\section{CONCLUSÕES}

a) A resistência à tração apresentada por três destes adesivos, cianoacrilato, albumina-glutaraldeído e gelatina-resorcinol-formaldeído-glutaraldeído, em alguns casos foi inferior a $100 \mathrm{gf}$.

b) Os adesivos de fibrina, de cianoacrilato e de albuminaglutaraldeído apresentaram melhores resultados que o controle, poliglactina 910 , quanto ao tempo de operação. O adesivo gelatina-resorcinol-formaldeído-glutaraldeído mostrou resultado semelhante.

c) Os resultados clínicos foram melhores com o adesivo de fibrina, e em ordem decrescente a poliglactina 910 e o cianoacrilato e não aceitáveis com o adesivo de albuminaglutaraldeído e adesivo de gelatina-resorcinol-formaldeído-glutaraldeído.

d) Os resultados histopatológicos foram melhores com o adesivo de fibrina e em ordem decrescente a poliglactina $910 \mathrm{e}$ o cianoacrilato e não aceitáveis com o adesivo de albumina-glutaraldeído e adesivo de gelatina-resorcinol-formaldeído-glutaraldeído.

\section{AGRADECIMENTOS}

Aos colegas Olavo Gomes Pereira Filho e Cláudio Shinzato, pela colaboração nos procedimentos cirúrgicos. A Fernando Chahud, responsável pelo estudo histopatológico. Aos Laboratórios que nos ofereceram seus adesivos: Centeon, o Beriplast- $\mathrm{P}^{\circledast}$, B. Braun, o Histoacry ${ }^{\circledR}$, Cryolife, o Bioglue ${ }^{\circledR} \mathrm{e}$ Cirumédica, o Colagel $^{\circledR}$. 


\section{ABSTRACT}

Purpose: To measure the duration of the operation, the strength of tissue adhesion, and to perform a clinical and histopathological study of ocular reinsertion of superior rectus muscles of rabbits with four different tissue adhesives, as an alternative to the use of polyglactin suture in strabismus surgeries. Methods: One hundred New Zealand rabbits were used for two experiments: I-A and I-B, with fifty rabbits for each experiment. These groups were further divided into five groups of ten rabbits (twenty eyes), which were subjected to the removal of the superior rectus muscle of both eyes, either with suture (control) or tissue adhesive: polyglactin 910, 6-0 suture and tissue adhesives made of fibrin, cyanoacrylate, albumin-glutaraldehyde and gelatine-resorcinol-formaldehyde-glutaraldehyde. The rabbits in experiment I-A were subjected to dynamometry for ten minutes following repositioning of the muscle. The rabbits in experiment I-B were subjected to clinical evaluation and to histopathologic evaluation. Results: Better performance of the tissue adhesives in relation to the time taken to carry out the surgery was observed. None of the adhesives met the parameters used for strength, that is, in some cases the reinserted muscle did not resist to the application of forces up to $100 \mathrm{gf}$. The clinical and histopathologic evaluations showed that only the fibrin adhesive presented a better performance than the polyglactin suture while the other results were worse than those of the controls (suture). Conclusion: It was observed that the adhesives studied are not suitable for strabismus surgeries.

Keywords: Tissue adhesives; Oculomotor muscles/surgery; Strabismus/surgery; Fibrin tissue adhesive/therapeutic use; Polyglactin 910; Sutures; Rabbits

\section{REFERÊNCIAS}

1. Reece TB, Maxey TS, Kron IL. A prospectus on tissue adhesives. Am J Surg 2001;182(2 Suppl):40S-4S.

2. Dunlap EA, Dunn M, Rossomondo R. Adhesives for sutureless muscle surgery. Arch Ophthalmol. 1969;82(6):751-5.

3. Ricci B, Ricci F, Bianchi P. Octyl 2-cyanoacrilate in sutureless surgery of extraocular muscles: an experimental study in rabbit model. Graefes Arch Clin Exp Ophthalmol. 2000;238(5):454-8.

4. Villaseñor-Solares J, Aguirre-Aquino B. Uso de adhesivos titulares en cirugía de estrabismo. Rev Bras Oftalmol. 1998;57(3):273-7.

5. Aichmair MW, Aichmair H, Lintner F. Fibrin gluing of the extraocular eye muscles. Experimental use in the rabbit. Klin Monatsbl Augenheilkd. 1988; 193(5):499-503. German.

6. Aichmair H. Fibrinklebung am äuBereren augenmuskel. In: Buschmann W, Mester U, Fibrinklebun in der Ophthalmochirurgie. Stuttgart: Enke; 1995. p.61-3.

7. Spierer A, Barequet I, Rosner M, Solomon AS, Martinowitz U. Reattachment of extraocular muscles using fibrin glue in a rabbit model. Invest Ophthalmol Vis Sci. 1997;38(2):543-6.

8. Moreira AT, Torres LFB, Scarpi MJ, Moreira Júnior CAM, Miranda SP, Matsumoto LH. Uso do adesivo biológico de fibrina para reinserção de músculos retos superiores em coelhos - I. Estudo clínico. Rev Bras Oftalmol. 1998;57 (7):501-12.

9. Moreira AT, Torres LFB, Scarpi MJ, Moreira CAM, Miranda SP, Matsumoto LH. Uso do adesivo biológico de fibrina para reinserção de músculos retos superiores em coelhos - II. Estudo histopatológico. Rev Bras Oftalmol. 1998; 57(8):585-97.

10. Refojo MF, Dohlman CH, Koliopoulos JK. Adhesives in ophthalmology: a review. Surv Ophthalmol. 1971;15(3):217-36.

11. Radosevich M, Goubran HA, Burnouf T. Fibrin sealant: scientific rationale, production methods, properties, and clinical use. Vox Sanguinis. 1997;72(3): $133-43$.

12. Grupenmacher F, Abib FC. Estudo experimental do colagel - novo adesivo biológico em córnea de coelho. An Oftalmol. 1990;9:46-9.

13. Spera CA, Schellini SA, Silva MRB de M, Marques MEA, Rahal SC. Uso de colagel na cirurgia da conjuntiva. Arq Bras Oftalmol. 1998;61(2):152-8.

14. Herget GW, Kassa M, Riede UN, Lu Y, Brethner L, Hasse J. Experimental use of an albumin-glutaraldehyde tissue adhesive for sealing pulmonary parenchyma and bronchial anastomoses. Eur Jour Cardiothorac Surg. 2001;19(1):4-9.

15. Collins C. Orbital mechanics. Bach y Rita P, Collins C. The control of eye movements. New York: Academic Press; 1971. p.283-326.

16. Scott A. Extra ocular muscles forces in strabismus. In: Bach y Rita P, Collins C. The control of eye movements. New York: Academic Press; 1971. p.327-42.

17. Salthouse TN, Matlaga BF, Wykoff MH. Comparative tissue response to six sutures materials in rabbit cornea, sclera, and ocular muscle. Am J Ophthalmol. $1977 ; 84(2): 224-33$.

\section{ABO ELETRÔNICO A versão eletrônica dos Arquivos Brasileiros de Oftalmologia com textos completos está disponível em:}

$\begin{array}{ll}\text { ABO - } & \text { Arquivos Brasileiros de Oftalmologia } \\ \text { http://www.abonet.com.br }\end{array}$

- SciELO - Scientific Eectronic Library Online http://www.scielo.org

Free Medical J ournals - http://www.freemedicaljournals.com 